Wirkung des Chlorkalks auf Terpentinöl etc.

kann mil Kohle auch ganz im Kleinen arbeiten und in Glasflaschen Schnellessig aus Weingeist herstellen. (Kunstund Gewbl. für Bayern. 1852 - Chem-pharm. Centrbl. 1852. No. 14.)

$B$.

\title{
Wirkung des Chlorkalks auf Terpentinöl und andere flüchtige Oele.
}

Cha utard, Professor am Lyceum zu Vendòme, die Wirkung erwägend. welche sauerstoffreiche Körper, $\mathbf{z}$. B. Salpetersäure auf flüchtige Oele haben, suchte zu erforschen, wie sich Chlorkalk damit verhalten würde. Dieses that er um so eifriger, als er den starken Einfluss desselben auf Weingeist bei der Darstelluing des Chloroforms kannte. Cha utard glaubt, dass seine Versuche zur Bereitung wohlfeiler und nützlicher Producte geführt haben. Er sagt: mengt man in einer Retorte 24 Theile Wasser, $8 \mathrm{Th}$. Chlorkalk und 1 Th. Terpentinöl, so entsteht in der Wärme eine tumultuarische Reaction, es entwickelt sich eine grosse Menge Kohlensäuregas und es destillirt eine angenehm riechende Flüssigkeit über. Die Destillation geht ihren Gang bis zu Ende fort. Im Recipienten sieht man die Flissigkeit in drei Lagen getheilt, wovon die erste unangefochtenes Terpentinöl, die unterste eine dem Chloroform àhnliche ätherische Flüssigkeit, und die mittlere eine Auflösung der letzteren in Wasser ist, welche durch eine gelinde Destillation im Marienbade isolirt werden kann. Diese Art des Chloroforms ist sehr beweglich, schmeckt suisslich, hat einen sehr angenehmen Geruch und ist schwerer als Wasser. Die Elementar-Analyse ergab, dass es aus 10,47 Kohlenstoff, 1,03 Wasserstoff und 88,56 Sauersioff bestand, oder berechnet aus $\mathrm{C}=10.05, \mathrm{H}=0,84, \mathrm{O}=89,11$.

Den geringen Ueberschuss an Kohlenstoff glaubt Ch a u tard einer gewissen das Product stets begleitenden Menge von Kohlenwasserstoff zuschreiben zu müssen, welche aber mittelst einer Destillation über Schwefelsäure völlig entfernt werden konnte. Diese Ansicht dürfte den Unterschied erklären, welcher zwischen dem Siedpuncte des Products und dem des Chloroforms statt findet.

Im Grossen geräth die Operation am besten, wenn man dem Gemenge halb so viel Kalk zusetzt als Chlorkalk genommen war. Die Masse darf übrigens nur $1 / 4$ der Capacitäl des Destillationsgefässes einnehmen. Durch erwähnten Zusatz bleibt dann weniger Terpentinöl unzersetzt. Sehr gut ist's, hier einen bis an den Boden des Destillationsgefässes reichenden Umrührstab anzubringen, damit der Inhalt desselben inniger gemengt werden könne. 
Sind diese Vorkehrungen getroffen, so bringt man das Ganze scbnell in Hitze und entfernt das Feuer, sobald der Hals des Helms warm geworden ist. Die Reaction tritt dann ein und die Destillation geht dann, wie gesagt, ihren Gang bis zu Ende fort. Man kann diese Operation mit den alten Ingredienzien und der Hälfte des Terpentinöls noch einmal vornehmen. Dass hier der beste Chlorkalk genommen werden muss, versteht sich von selbst; ist er mit vielem Chlorcalcium beladen, so nimmt die Masse eine gewisse Zahigkeit an und kann bei der ersten Reaction so sehr steigen, dass sie die Helmröhren verstopft. Das auf obige Weise gewonnene Chloroform wird im Wasserbade rectificirt, und zwar indem man dafür sorgt, dass nur drei Fünftel davon übergehen. Es bleibt eine Kohlenwasserstoffverbindung zurück, die man zu einer neuen Operation aufbewahrt. Chautard bat mit Citronen-, Bergamott-, Pfeffermünz- und Copaivabalsamöl unter den erwähnten Úmständen ein dem Chloroform fast gleiches Product erhalten. Aus theoretischen Gruinden glaubte er, dass im Rückstande Ameisensäure entstanden sein miisste. Um dieses zu erfahren, schlug er folgenden Weg ein. Er versetzte die filtrirte Flüssigkeit des Rückstandes mit Schwefelsäure in Ueberschuss. sonderte das ausgeschiedene Kalksulfat ab und destillirte. Im Recipienten befand sich ein Gemenge von Ameisen- und Hydrochlorsäure. Diese neutralisirte er zu Natronsalzen, rauchte die Auflösung zur Trockne ab und trennte aus dem Ruickstande den grössıen Theil des ameisensauren Salzes durch weniges Wasser. In der Auflösung liess sich die Ameisensäure schon dadurch erkennen, dass sie das Silber in der Wärme metallisch niederschlug. Fixe Oele geben, wie das Terpentinöl, mil Chlorkalk kein Chloroform; doch lässt sich von der Reaction jenes auf erstere noch viel Interessantes erwarten.

Ein ausgezeichneter Chemiker in Paris bemerkt, dass so lehrreich die Arbeit Chautard's auch ist, sie doch in praktischer Hinsicht keine Vortheile darbieten kann, da man mit Alkohol viel mehr Chloroform gewinnt, als mit Terpentinöl; schon deshalb sei auch an die Anwendung des Terpentinchloroforms zum medicinischen Gebrauche nicht zu denken. Er sagt ferner, dass wenn letzteres selbst mit äusserster Vorsicht bereitet ist, es doch auf der Hand einen Terpentinölgeruch zurïcklässt. Die Darstellung desselben ist ubbrigens schwieriger und, wie schon oben angedeutet, theurer. (Journ. de Pharm. et de Chim. Fevr. 18.52. p. 88.)

du Mênil. 